\title{
Determining the Association of Benign and Malignant Salivary Gland Tumours with ABO-Rh Blood Groups
}

\section{Mahbobeh Oroei ${ }^{1}$}

Introduction:

\section{ABSTRACT}

Various studies have proposed that some ABO blood groups may be associated with increased risk of cancer. Hence, we decided to conduct this study to investigate the relationship between ABO-Rh blood group and risk of salivary gland tumor. Materials and Methods:

In this study, 190 patients with salivary gland tumor and 400 healthy persons were investigated. Demographical information including ABO blood group of both groups were collected and analyzed using the SPSS 18 version. Binary logistic regression (univariate and multivariate model) were applied with 95\% confidence interval.

\section{Results:}

The most common blood group in patients with salivary gland tumor was blood group $O$. There was no significant relationship between the ABO blood group and salivary gland tumor risk (All; $p>0.05$ ). The blood group $O$ and A were the most abundant blood groups in patients with the malignant and benign salivary gland tumor respectively (46.6\%, 35.7\%). The risk of malignancy of tumor in the patients with blood group O was marginal (1.84; 95\%CI: 0.96-3.53, p: 0.06).

Conclusion:

This study shows no relationship between ABO-Rh blood groups and salivary gland tumor risk. However, to reach a definitive conclusion about the risk of malignancy in blood group $O$, stronger studies are needed in the future.

Kevwords:

Salivary Gland Neoplasms; Blood-Group

$\mathrm{S}$ alivary gland tumors (SGT) constitute about 1-5\% of all head and neck tumors. The annual incidence of SGT is different in different parts of the world, ranging from 0.5 to 2 per $100,000 .{ }^{1}$ Tumors are mostly located in the major glands, especially in the parotid gland; $10 \%$ to $20 \%$ occur in the minor salivary glands. ${ }^{2}$ Majority of these, almost $80 \%$, are benign and only $20 \%$ are malignant. The prevalence of malignant tumours is $20-25 \%$ in the parotid glands, $40 \%$ in the submandibular glands, and about $90 \%$ in sublingual gland. ${ }^{1,3}$ The most common cancer is mucoepidermoid carcinoma in the parotid glands and adenoid cystic carcinoma in the submandibular and minor salivary glands. ${ }^{4}$

SGTs, in both the major and minor salivary glands, often present as enlarging masses without pain. The majority of these tumors can be treated with surgical excision alone, while adjuvant therapy in the form of chemoradiotherapy may be required for high-grade tumors and advanced tumours with metastasis.

Most head and neck cancers are strongly etiologically related to lifestyle factors such as smoking, alcohol consumption and diet. But based on present knowledge, these agents do not play a role in SGTs. Factors such as employment at rubber manufacturing units, woodworking, hairdressing, history of Epstein-Barr virus infection, immunosuppression, cancer and radiation may be related with SGTs. ${ }^{5,6}$

Cancer is multifactorial; besides lifestyle and environmental factors, genetics and heredity have important role in causing cancer.

1 - Hearing Disorders Research Center, Loghman hakim Hospital, Shahid Beheshti University of Medical Sciences

Corresponding author:

Dr Mahbobeh Oroei

email: oroei3m@gmail.com 
Various studies have proposed the relationship between the $\mathrm{ABO}$ blood groups and some cancers. ${ }^{7-11}$ The first report, about association between gastric cancer and blood group A was published in 1953. ${ }^{12}$ The antigens of blood groups are widely expressed on the membranes of red blood cell, epithelia, platelets, sensory neurons and vascular endothelia, and also body fluids. ${ }^{13}$ Underlying mechanisms of this association are unclear. There is growing evidence regarding role of ABO blood group in the development of neoplastic and other disorders. ${ }^{7,13-15}$

Based on literature review, there is paucity of studies about association between SGTs and ABO blood groups. There were conflicting reports about the relationship between the ABO blood groups and these tumors. ${ }^{16,17}$ Therefore, we decided to conduct this study to evaluate the relationship between SGT and ABO blood group.

\section{Material and Methods}

A total of 190 patients with salivary gland tumor who were admitted between March 2007 and September 2017 and consented to participate, were enrolled in the study. All patients had definitive diagnosis of a salivary gland tumor based on International Classification of Diseases for oncology (ICD-O)-10th edition. Patients with any other malignant diseases were excluded. A control group was selected from outpatients visiting the hospital during the same period as the case group but having no evidence of salivary gland diseases or any cancer. The number of control subjects was 400 (two controls for each case). Detailed information of the cases such as gender, age, history of smoking, and ABO blood group were obtained from the medical records. In control group, in addition to similar information, the blood group was determined.

\section{Statistical Analysis:}

Independent t- test was applied to compare quantitative variables without skewed distribution. Chi square test was used to compare the proportions. The study population was categorized into two groups based on age with 60 years being the watershed line. The proportions of ABO blood groups were compared between case and control groups. We conducted unconditional logistic regression

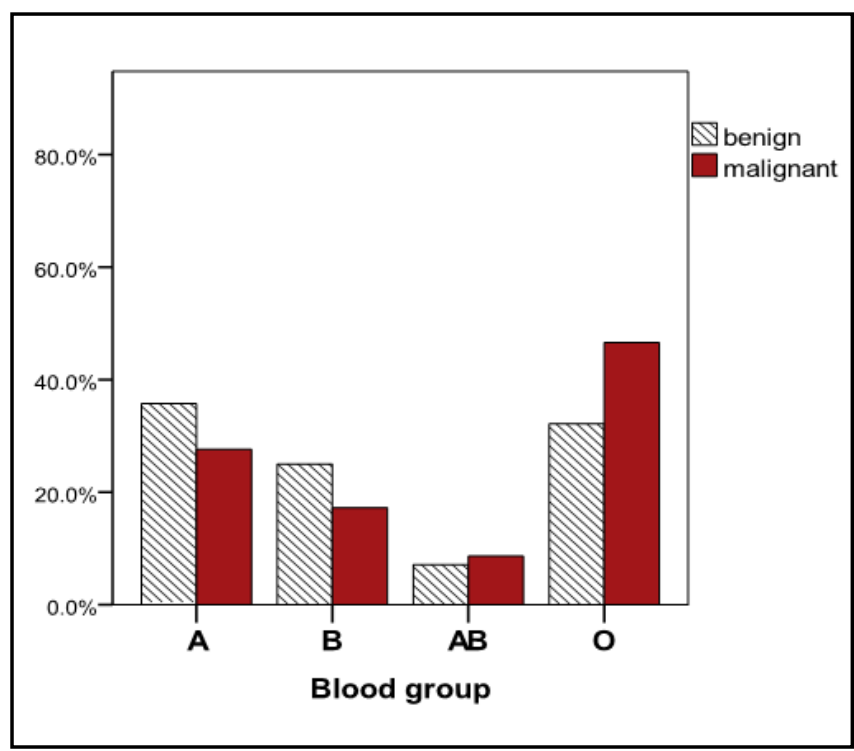

Fig. 1: ABO distribution in the patients with benign / malignant salivary gland tumor

to determine the association between $\mathrm{ABO}$ blood group and risk of SGT (with $95 \% \mathrm{CI}$ ). We calculated odds ratios in age groups after adjusting for gender. We analyzed separately the cases based on nature of tumor (benign or malignant) and assessed the relationship of those tumors with ABO blood groups. All statistical analyses were performed with SPSS version 18 for Windows.

\section{Results}

\section{Overall study groups:}

This study investigated 190 patients with SGTs and 400 controls. Majority of the cases were male (58.4\%). The mean age was $45.6( \pm 17.3)$ years for case group and $47.0( \pm 7.7)$ years for control group. Of the cases, $34.3 \%$ were smokers and $5 \%$ had past history of alcohol consumption. Table I shows the characteristics of cases and controls, and demonstrates no statistically significant differences in studied variables between the two groups except age. The proportion of persons 60 years of age or older was higher in case group than control group ( 22.5 vs. $4.5 \%$, Odds ratio: $6.15 ; 95 \% \mathrm{CI}$ : $3.43-11.03, \mathrm{p}<0.001)$.

ABO blood group and risk of salivary gland tumours: 
Of the case group, only for 170 patients, ABO blood group was recorded in medical profile. Sixty-three (37.1\%) had blood group O, 59 (32.9\%) had blood group A, 38 (22.4\%) had blood group B and 13 (7.6\%) had blood group AB. No statistically significant relation was found between SGT and ABO blood groups. (Table I) The proportion of $\mathrm{ABO}$ blood groups in the control group was similar to Iranian population. ${ }^{18}$

The distribution of $\mathrm{ABO}$ blood groups in the cases group had significant difference based on age (p:0.04). The most common blood group in the cases $<60$ years was blood group A (34.9\%), and in the cases $\geq 60$ years, it was blood group O (46.2\%).

Table II shows the results of logistic regression analyses in two age groups adjusted for sex. We found no significant relationship between $\mathrm{ABO}$ blood groups and SGT. The proportion of Rh blood group also did not have significant difference between case and control groups (p:0.25).

Of all the SGTs, 124 were benign (117 in parotid glands, 4 in submandibular glands and 3 in palate) and 66 were malignant (52 in parotid glands and 14 in submandibular glands).

We assessed some variables in the patients with benign and malignant tumours. (Table III) The results showed that the risk of malignancy in the patients with age $\geq 60$ years was 2.02 -fold of the risk in younger patients. The most common blood group in benign tumours was $\mathrm{A}(\mathrm{n}=40,35.7 \%)$ and in malignant tumors was $\mathrm{O}(\mathrm{n}=27,46.6 \%)$. (Fig. 1). Patients with blood

Table I: Baseline Characteristics of SGT cases and control group

\begin{tabular}{|c|c|c|c|c|}
\hline VARIABLES & CASES $(\mathrm{N}=190)$ & $\begin{array}{c}\text { CONTROLS } \\
(\mathrm{N}=400)\end{array}$ & $\begin{array}{l}\text { CRUDE OR } \\
(95 \% \mathrm{CI})\end{array}$ & P-VALUE \\
\hline Age & $45.6 \pm 17.30$ & $47.0 \pm 7.77$ & $1.011(0.10-1.03)$ & 0.17 \\
\hline \multicolumn{5}{|c|}{ Gender } \\
\hline Male & $111(58.4)$ & $244(61.0)$ & $1.113(0.78-1.58)$ & \multirow{2}{*}{0.59} \\
\hline Female & $79(41.6)$ & $156(39.0)$ & 1 & \\
\hline \multicolumn{5}{|c|}{ Age group } \\
\hline$<60$ & $147(77.4)$ & $382(95.5)$ & 1 & \multirow{2}{*}{$<0.001$} \\
\hline$\geq \mathbf{6 0}$ & $43(22.6)$ & $18(4.5)$ & $6.15(3.43-11.03)$ & \\
\hline \multicolumn{5}{|c|}{ Smoking } \\
\hline Yes & $65(34.2)$ & $110(27.5)$ & $0.73(0.50-1.05)$ & \multirow{2}{*}{0.1} \\
\hline No & $125(65.8)$ & $290(72.5)$ & 1 & \\
\hline \multicolumn{5}{|c|}{ ABO blood group } \\
\hline $\mathbf{A}$ & $59(32.9)$ & $144(36.0)$ & $1.14(0.78-1.67)$ & 0.48 \\
\hline B & $38(22.4)$ & $74(18.5)$ & $0.78(0.51-1.23)$ & 0.29 \\
\hline $\mathbf{A B}$ & 13(7.6) & $33(8.2)$ & $1.08(0.56-2.12)$ & 0.81 \\
\hline $\mathbf{O}$ & $63(37.1)$ & $149(37.3)$ & $1.00(0.78-1.67)$ & 0.97 \\
\hline
\end{tabular}


Table II: The Risk of Salivary Gland Tumor and ABO-Rh blood group

\begin{tabular}{|c|c|c|c|c|c|c|}
\hline \multirow{2}{*}{ VARIABLES } & \multicolumn{2}{|c|}{ CASES $(\mathbf{N}=190)$} & \multicolumn{2}{|c|}{ CONTROLS $(\mathrm{N}=400)$} & \multirow{2}{*}{$\begin{array}{l}\text { CRUDE OR } \\
(95 \% \text { CI })\end{array}$} & \multirow{2}{*}{$\begin{array}{c}\text { P- } \\
\text { VALUE }\end{array}$} \\
\hline & NO. & $\%$ & NO. & $\%$ & & \\
\hline \multicolumn{7}{|c|}{ ABO $($ Age $<60)$} \\
\hline O vs others & 44 & 34.1 & 142 & 37.2 & $1.14(0.75-1.74)$ & 0.54 \\
\hline A vs others & 45 & 34.9 & 137 & 35.9 & $1.03(0.69-1.59)$ & 0.84 \\
\hline B vs others & 33 & 25.6 & 71 & 18.6 & $0.67(0.42-1.08)$ & 0.09 \\
\hline AB vs others & 7 & 5.4 & 32 & 8.4 & $1.57(0.67-3.65)$ & 0.29 \\
\hline$A+B+A B$ vs other & 85 & 65.9 & 240 & 60 & $0.88(0.58-1.33)$ & 0.54 \\
\hline RH+ & 119 & 92.2 & 340 & 89 & $0.66(0.32-1.35)$ & \multirow{2}{*}{0.25} \\
\hline RH- & 10 & 7.8 & 42 & 11 & 1 & \\
\hline \multicolumn{7}{|c|}{ ABO $($ Age $>=60)$} \\
\hline O vs others & 18 & 46.2 & 7 & 38.9 & $0.80(0.31-2.45)$ & 0.59 \\
\hline A vs others & 10 & 25.6 & 7 & 38.9 & $1.91(0.56-6.54)$ & 0.3 \\
\hline B vs others & 5 & 12.8 & 3 & 16.7 & $1.36(0.29-6.44)$ & 0.7 \\
\hline AB vs others & 6 & 15.4 & 1 & 5.6 & $0.31(0.03-2.84)$ & 0.3 \\
\hline $\mathbf{A}+\mathbf{B}+\mathbf{A} \mathbf{B}$ vs other & 21 & 53.8 & 11 & 61.1 & $1.41(0.41-4.88)$ & 0.59 \\
\hline RH+ & 38 & 97.4 & 16 & 88.9 & $0.20(0.02-2.48)$ & \multirow{2}{*}{0.21} \\
\hline RH- & 1 & 2.6 & 2 & 11.1 & 1 & \\
\hline
\end{tabular}

Odds ratio (OR) was adjusted based on sex variable. The significant level was considered less than 0.05.

group $\mathrm{O}$ had marginally increased risk of malignancy compared to non-O blood groups (Odds ratio: 1.84; 95\% CI: 0.96-3.53, p: 0.06). Other blood groups did not definitely have a significant relationship, after adjusting for age and sex. (Table III)

\section{Discussion}

Recently, various studies have been performed for showing the association between blood groups and risk of cancer. A few studies have also been done on the relationship between salivary gland tumors and $\mathrm{ABO}$ blood group.

In this study, we observed the same relative frequency of blood groups $\mathrm{A}$ and $\mathrm{O}$ in cases with age younger than 60 years old and the blood group $\mathrm{O}$ was found to be predominant in older age. However, there was no statistically significant relationship between $\mathrm{ABO}$ blood groups and SGT. Pinkston et al. ${ }^{19}$ and Garret et al. ${ }^{16}$ reported no relationship between SGT and ABO blood group; Pinkston has rather reported a lower percentage of blood group A in cases than control group..$^{19}$ Osborne et al. showed this relationship and also reported a high incidence of SGT in blood group A. ${ }^{17}$ In contrast to our study, they found blood group A as the most common group in the patients followed by group $\mathrm{O}$. A recent systematic review and meta-analysis suggested that blood group A was associated with increased cancer incidence; however these results had a limitation for 
Table III: The comparison between benign and malignant tumor

\begin{tabular}{|c|c|c|c|c|}
\hline VARIABLES & BENIGN & MALIGNANT & OR(95\%CI) & P-VALUE \\
\hline \multicolumn{5}{|c|}{$\operatorname{Sex}(n, \%)$} \\
\hline Male & $72(64.9)$ & 39(35.1) & $1.04(0.57-1.91)$ & \multirow{2}{*}{0.89} \\
\hline Female & $52(65.8)$ & $27(34.2)$ & 1 & \\
\hline \multicolumn{5}{|c|}{ Age group (n,\%) } \\
\hline Age $<60$ & $100(69.0)$ & $45(31.0)$ & 1 & \multirow{2}{*}{0.04} \\
\hline Age $>=60$ & $22(52.4)$ & $20(47.6)$ & $2.02(1.00-4.07)$ & \\
\hline \multicolumn{5}{|c|}{ Smoking (n,\%) } \\
\hline Yes & $43(66.2)$ & $22(33.8)$ & $0.94(0.50-1.77)$ & 0.85 \\
\hline No & 81(64.8) & $44(35.2)$ & 1 & - \\
\hline \multicolumn{5}{|c|}{ Anatomical Site (n,\%) } \\
\hline Parotid & $117(69.2)$ & $52(30.8)$ & 1 & - \\
\hline Sub maxillary & $4(22.2)$ & $14(77.8)$ & \multirow{2}{*}{$4.50(1.71-11.80)$} & \multirow{2}{*}{$<0.001$} \\
\hline Accessory & $3(100.0)$ & $\mathbf{0}(0.0)$ & & \\
\hline \multicolumn{5}{|c|}{ Side (n,\%) } \\
\hline Left & $74(69.8)$ & $32(30.2)$ & $0.64(0.35-1.16)$ & 0.14 \\
\hline Right & 48(59.3) & $33(40.7)$ & $1.58(0.87-2.89)$ & 0.13 \\
\hline Bilateral & $2(66.7)$ & $1(33.3)$ & $0.99(0.08-10.55)$ & 0.94 \\
\hline Size (mean \pm sd.) $\mathrm{cm}$ & $3.2 \pm 1.5$ & $4.5 \pm 3.0$ & $1.29(1.09-1.53)$ & $<0.001$ \\
\hline $\begin{array}{l}\text { Duration (median, } \\
\text { range)month }\end{array}$ & $24(1,300)$ & $12(1,240)$ & $0.99(0.98-1.00)$ & 0.34 \\
\hline \multicolumn{5}{|c|}{ ABO blood group $(n, \%) *$} \\
\hline A vs others & $40(71.4)$ & $16(28.6)$ & $0.69(0.34-1.37)$ & 0.27 \\
\hline B vs other & $28(73.7)$ & $10(26.3)$ & $0.67(0.29-1.59)$ & 0.35 \\
\hline AB vs others & $8(61.5)$ & $5(38.5)$ & $1.07(0.32-3.56)$ & 0.91 \\
\hline O vs others & $36(57.1)$ & 27(42.9) & $1.84(0.96-3.53)$ & 0.06 \\
\hline RH+ & $103(64.8)$ & $56(35.2)$ & $2.29(0.47-11.15)$ & \multirow{2}{*}{0.3} \\
\hline RH- & $9(81.8)$ & $2(18.2)$ & 1 & \\
\hline
\end{tabular}

*Odds ratio of blood group were adjusted for sex and age group. The significant level was considered less than 0.05 . 
SGT, because only one study was included in this analysis. ${ }^{10}$ In another recent study, Singh et al. had a near agreement with our results; they have reported a more or less even distribution of ABO blood group in patients with SGT and the most common blood group was blood group O.?

On the other hand, we found, by univariate and multivariate analyses, that blood group $\mathrm{O}$ might be a risk factor for malignancy in the patients with SGT. The blood group $\mathrm{O}$ had been reported as a poor prognostic factor for the patients with laryngeal cancer, whereas it was found a protective factor in the patients with nasopharyngeal carcinoma and other cancers. ${ }^{8,13,20}$ Osborne et al in their study found high frequency of blood group A in malignant SGT. We calculated odds ratio using data of that study for comparison, so odds ratio of malignancy for blood group A was $1.133(95 \% \mathrm{CI}$ : $0.80-1.60)$ and for blood group $\mathrm{O}$ was $0.923(95 \% \mathrm{CI}$ : 0.64-1.31). These results were not significant, but it was almost borderline for blood group A in Osborne study. However the prognostic value of ABO blood group have been suggested in cardiovascular diseases and some cancers, but the evidence is not enough and it requires more studies to understand underlying pathophysiological mechanisms. ${ }^{13}$

ABO antigens were discovered in the early 1900s. These antigens are expressed on red blood cells, platelets, epithelial and endothelial cells. Aird et al in 1953, suggested the association between ABO blood group and risk of gastric cancer. ${ }^{12}$ Moreover, various studies have corroborated this possible association. It was discussed that this observed association cannot be due to $\mathrm{ABO}$ blood antigens, but they may have an effect on genes located close to ABO blood group genes. The underlying mechanisms have been proposed to explain these findings, but the main molecular mechanisms are still unknown, and scientific research on this subject is growing. Since the distribution of ABO blood group can widely vary among different races and ethnicities in the world, ${ }^{21,22}$ more studies are needed in various regions of the world with different head and neck cancers.

The limitations of our study should be accepted. First, the number of the patients with accessory salivary gland tumours was few. Second, our study was conducted in a single center, and our participants enrolled mostly from
Tehran province. To further investigate the borderline risk of blood group $\mathrm{O}$, it can be conducted in other settings with appropriate sample size including more accessory salivary gland tumors.

\section{Conclusion}

Our results showed no relationship between ABO-Rh blood group and salivary gland tumour. But considering wide genetic differences among people in different parts of the world and environmental factors, it is suggested to do further studies in other populations to confirm or disapprove our findings.

\section{Acknowledgement}

The authors would like to thank the Clinical Research Development Unit (CRDU) of Loghman Hakim Hospital, Shahid Beheshti University of Medical Sciences, Tehran, Iran for their cooperation.

\section{References}

1. To VSH, Chan JYW, Tsang RKY, Wei WI. Review of Salivary Gland Neoplasms. ISRN Otolaryngology 2012; Article ID 872982, 6 pages, 2012. https://doi.org/10.5402/2012/872982

2. Sardar M, Ganvir S, Hazarey V. A demographic study of salivary gland tumors. SRM Journal of Research in Dental Sciences 2018; 9(2):67-73

3. Speight PM, Barrett AW. Salivary gland tumours. Oral diseases 2002; 8(5):229-40

4. Luksic I, Virag M, Manojlovic S, Macan D. Salivary gland tumours: 25 years of experience from a single institution in Croatia. Journal of cranio-maxillo-facial surgery : official publication of the European Association for Cranio-MaxilloFacial Surgery 2012; 40(3):e75-81

5. Horn-Ross PL, Ljung BM, Morrow M. Environmental factors and the risk of salivary gland cancer. Epidemiology (Cambridge, Mass) 1997; 8(4):414-9

6. Swanson GM, Burns PB. Cancers of the salivary gland: workplace risks among women and men. Annals of epidemiology 1997; 7(6):369-74

7. Singh K, Kote S, Patthi B, Singla A, Singh S, Kundu H, et al. Relative risk of various head and neck cancers among different blood groups: an analytical study. Journal of clinical and diagnostic research: JCDR. 2014; 8(4):ZC25-ZC28

8. Sheng L, Sun X, Zhang L, Su D. ABO blood group and 
nasopharyngeal carcinoma risk in a population of Southeast China. International journal of cancer 2013; 133(4):893-7

9. Akhtar K, Mehdi G, Sherwani R, Sofi L. Relationship between various cancers and $\mathrm{ABO}$ blood groups-A Northern India experience. Int J Pathol. 2010; 13(1):3-7

10. Zhang B-L, He N, Huang Y-B, Song F-J, Chen K-X. ABO blood groups and risk of cancer: a systematic review and metaanalysis. Asian Pac J Cancer Prev. 2014; 15(11):4643-50

11. Jaleel BF, Nagarajappa R. Relationship between ABO blood groups and oral cancer. Indian journal of dental research : official publication of Indian Society for Dental Research 2012;23(1):7-10

12. Aird I, Bentall HH, Roberts JF. Relationship between cancer of stomach and the ABO blood groups. British medical journal 1953; 1(4814):799

13. Franchini M, Liumbruno GM, Lippi G. The prognostic value of ABO blood group in cancer patients. Blood Transfusion 2016; 14(5):434

14. Anstee DJ. The relationship between blood groups and disease. Blood. 2010:blood-2010-01-261859.

15. Ewald DR, Sumner SCJ. Blood Type Biochemistry and Human Disease. Wiley interdisciplinary reviews Systems biology and medicine 2016; 8(6):517-35

16. Garrett JV, Nicholson A, Whittaker JS, Ridway JC. Blood- groups and secretor status in patients with salivary-gland tumours. Lancet (London, England) 1971; 2(7735):1177-9

17. Osborne RH, De George FV. The ABO blood groups in parotid and submaxillary gland tumors. American journal of human genetics 1962; 14(2):199

18. Ravari A, Javadinasab M, Ebadi A, Mottahedian E, Sadeghi M, Hamedanizade F, et al. Correlation between type of blood group and post 10operative bleeding in coronary artery bypass graft surgery. Iranian Journal of Critical Care Nursing (IJCCN) 2008; 1(1):1-4

19. Pinkston JA, Cole P. ABO blood groups and salivary gland tumors (Alabama, United States). Cancer causes \& control : CCC. 1996; 7(6):572-4

20. Jin T, Li PJ, Chen XZ, Hu WH. ABO blood group is a predictor of survival in patients with laryngeal cancer. Chinese journal of cancer 2016; 35(1):90

21. Liu J, Zhang S, Wang Q, Shen H, Zhang Y, Liu M. Frequencies and ethnic distribution of $\mathrm{ABO}$ and $\mathrm{RhD}$ blood groups in China: a population-based cross-sectional study. BMJ Open 2017; $7(12)$

22. Torabizade maatoghi J, Paridar M, Mahmodian Shoushtari M, Kiani B, Nori B, Shahjahani M, et al. Distribution of ABO blood groups and rhesus factor in a large scale study of different cities and ethnicities in Khuzestan province, Iran. Egyptian Journal of Medical Human Genetics 2016; 17(1):105-9. 